\title{
Secreto profesional y riesgo vital para un tercero identificado: metodología de análisis ético en torno a un caso.
}

Professional secrecy and vital risk for an identified third party: ethical analysis methodology based on a case.

\begin{abstract}
Javier Barbero Gutiérrez a, Marina Sánchez Caballero ${ }^{\text {, }}$, Jesús M $^{\mathrm{a}}$ Martín Cortecero ${ }^{\mathrm{c}}$.
${ }^{a}$ Psicólogo Adjunto. Servicio de Hematología. Hospital Universitario La Paz, Madrid, España. ${ }^{b}$ Psicóloga Interna Residente. Servicio de Salud Mental. Hospital Universitario de Getafe, Madrid, España. ${ }^{c}$ Psicólogo Investigador. Departamento de Neurociencia. Facultad de Medicina de la UAM, Madrid, España.
\end{abstract}

Correspondencia: Javier Barbero Gutiérrez, (javierbarberogutierrez@gmail.com)

Recibido: 29/10/2012; aceptado: 12/01/2013

\begin{abstract}
RESUMEN: Los valores éticos aparecen permanentemente en la práctica clínica. Cuando entran en conflicto, necesitamos metodologías de análisis ético que permitan minimizar el riesgo de error. Presentamos un caso en que el paciente afirma que puede reaccionar matando a su hermano si éste le provoca. El psicólogo vive el conflicto de respetar el secreto profesional o de denunciar el riesgo de agresión a un tercero identificado, bien a la potencial víctima, bien a otros familiares, bien a las autoridades. Entran en conflicto el valor de la confidencialidad (principio de autonomía) y el valor de la salud y la vida de un tercero (principio de no-maleficencia). Se considera también el análisis de consecuencias. Se analiza el caso desde las perspectivas deontológica, jurídica y bioética utilizando, en este último caso, una metodología racional ampliamente consensuada.

PALABRAS CLAVE: Confidencialidad, Deber de Advertencia, Análisis Ético, Metodología, Bioética.
\end{abstract}

\begin{abstract}
Ethical values permanently appear in clinical practice. When they conflict with each other, we need ethical analysis methodologies that enable us to minimize the risk of error. A case is presented where the patient affirms that he can react killing his brother if he's provoked by him. The psychologist has to decide whether to respect the professional secret or to report the aggression risk to a third party, either to the potential victim, to other family members, or to the authorities. Confidentiality value (autonomy principle) conflicts with the health and life of a third party value (nonmaleficence principle). The analysis of consequences is also considered. The case is analyzed from a deontological, juridical and bioethical perspective using, in this last case, a largely contrasted rational methodology. KEY WORDS: Confidentiality, Duty to Warn, Ethical analysis, Methodology, Bioethics.
\end{abstract}

\section{Introducción}

En el trabajo clínico como psicólogo surgen conflictos éticos que no pueden ser resueltos por la mera intuición, sino que necesitan de un método de análisis específico que facilite la buena praxis. La confidencialidad, como uno de los ejes centrales del trabajo técnico y ético del psicólogo requiere preservar la información conocida y transmitida por el paciente, así como la confianza que éste deposita en el profesional con el que mantiene un vínculo terapéutico. No mantener la confidencialidad de los datos supone romper el secreto profesional.

El secreto profesional está recogido en los códigos deontológicos de los colegios profesionales (1) como condición de posibilidad para llevar a cabo una buena 
praxis. Romper este secreto es un acto punible por las comisiones deontológicas de dichos colegios. Sin embargo, ¿qué sucedería si esta obligación entra en conflicto con la responsabilidad de preservar la salud y la vida de un tercero identificado? Sería el caso de un paciente que informa al clínico de su intención de matar a una persona concreta.

Los objetivos de este artículo son exponer un proceso de análisis ético, con metodología contrastada en torno a un caso real, extremo pero paradigmático, vinculado al valor de la confidencialidad, reflexionar sobre el papel modulador de los valores en la intervención psicoterapéutica y, por último, abordar el papel de terceros identificados en el proceso de la terapia cuando no son interlocutores directos de la misma.

En primer lugar, realizaremos una descripción del caso clínico. Posteriormente, expondremos una revisión bibliográfica del estado de la cuestión, de casos recogidos en la literatura así como un análisis deontológico y jurídico al respecto. A continuación, detallaremos el modelo de análisis y deliberación ética propuesto por el profesor Diego Gracia (2) aplicándolo al caso. Finalmente, expondremos las reflexiones y recomendaciones pertinentes respecto a la posible resolución del mismo.

\section{Descripción del caso clínico}

Varón hemofílico de 39 años, el menor de cuatro hermanos (3 varones), de madre portadora de hemofilia fallecida hace 15 años y padre no portador fallecido hace 4. Se encuentran también antecedentes de hemofilia en la familia materna. Ninguno de sus hermanos padece la enfermedad. En la actualidad, reside en el domicilio familiar a las afueras de una capital de provincia, junto con uno de sus hermanos.

El paciente fue diagnosticado a los 6 años de hemofilia A moderada con una cuantificación de factor VIII del 6\%. A raíz de un ingreso realizado a sus 15 años para tratamiento de un episodio de hemartros, se realiza por primera vez una prueba Elisa para determinar la existencia de anticuerpos de VIH, resultando positiva. También dio positivo en la serología del virus de la hepatitis C.

Teniendo 37 años se le deriva al servicio de Reumatología por repetidas quejas acerca de dolores articulares. El juicio clínico concluye que se trata de poliartralgias inespecíficas, descartándose artritis en ese momento.

El paciente, aconsejado por otros profesionales y algunos familiares, decide solicitar consulta con el Psicólogo del Servicio de Hematología porque está viviendo mucho malestar que además interfiere con la adhesión a los tratamientos. Hasta el momento solo se habían podido realizar intervenciones "de pasillo" encaminadas a la contención emocional. Anteriormente ya se le había planteado la posibilidad de recibir atención psicológica pero rechazó tajantemente la misma. 
En las sesiones de terapia con el Psicólogo Adjunto del Servicio de Hematología está presente un psicólogo en formación, con consentimiento del paciente. En la consulta el paciente expresa numerosas quejas sobre dolor osteo-articular, sin embargo, rechaza cualquier tipo de tratamiento frente a éste; también refiere problemas de sueño, aumento de agresividad, pérdida de interés por la vida y la motivación por luchar, sensación de desesperanza, antecedentes de ideación suicida, anhedonia, astenia, apatía, reacciona al humor y muestra buena capacidad metarepresentacional. La terapia psicológica es, hasta el momento, el único vínculo estable que mantiene con el sistema sanitario, aunque sí que acude a buscar factor para la coagulación. Rechaza también tratamiento farmacológico psiquiátrico.

En numerosas ocasiones expresa una gran rabia hacia los profesionales sanitarios al considerarlos como los responsables de su infección por VIH, debido a que había estado recibiendo tratamiento transfusional desde los 6 años y hasta enero de 1987 (cuando él tenía 15 años) no entró en vigor la normativa de escrutinio obligatorio de anticuerpos VIH en donantes. Esto deriva en una falta de confianza con los profesionales sanitarios. El paciente relata que "el hospital me metió el VIH". Manifiesta también una vivencia intensamente egodistónica de su infección por VIH. Es conocida exclusivamente por sus hermanos/cuñados.

Mantenía una buena relación con sus padres pero desde que éstos fallecen argumenta que solo vive odio. Expresa tener una buena relación con uno de sus hermanos, su hermana y sus cuñados pero relata una historia continua de conflictos con el único hermano conviviente, a quién acusa de provocarle de manera significativa para entrar en enfrentamientos.

Se plantea al paciente poder conectar con la parte de la familia con la que mantiene buena relación y con otros profesionales que le han venido atendiendo, en la búsqueda de desarrollar factores de protección y de apoyo ante la situación de bloqueo y angustia, pero el paciente se niega explícitamente a ello.

El paciente ha experimentado la impotencia de sentirse más débil (su salud está muy quebrada) en estos enfrentamientos con su hermano y relata ideación homicida si tuviera un arma a su alcance. Dice haber conseguido esa arma -que no quiere especificar cuál es- y que no va a tolerar ninguna provocación más de su hermano. Manifiesta no importarle ni morir ni matar en ese enfrentamiento, si llega el caso. Tras esta descripción del caso clínico nos planteamos si estaría justificada éticamente la ruptura del secreto profesional acerca de las intenciones agresivas del paciente, ruptura tanto en relación al entorno privado como en relación a las autoridades. 


\section{Estado de la cuestión}

\subsection{Revisión de la literatura: Algunos casos paradigmáticos}

Han habido varios antecedentes históricos de casos similares al anteriormente descrito, en los que la salud o la vida de un tercero identificado se encontraban en peligro. Esto nos introduce en un conflicto en torno a la confidencialidad, con dos sujetos que pueden ser afectados significativamente. El profesional sanitario tiene la responsabilidad de hacer respetar al máximo los dos valores que entran en conflicto, es decir, la autonomía moral del que no quiere que sus intenciones o sus conductas puedan ser visibilizadas y el valor de la salud y/o de la vida del otro afectado.

\section{A) Caso Tarasoff}

En 1968, Prosenjit Poddar, natural de la India, conoce a Tatiana Tarasoff en una universidad californiana. Comienzan una relación que Poddar subjetivamente valora como muy seria. Esto provoca en Tatiana el deseo de romper la relación, lo que desencadena que Poddar precise atención psiquiátrica. En Agosto de 1969, fue visto por el Dr. Stuart Gold, quién le prescribió antipsicóticos y, posteriormente, le derivó al psicólogo Lawrence Moore. A pesar de los fármacos y de la terapia que comenzó con Moore, Poddar seguía con la ilusión de volver con Tatiana. En una de las sesiones, Poddar reveló al terapeuta su intención de matar a una mujer, siendo ésta identificada por Moore como Tatiana. Ante esta revelación, el psicólogo notificó a la policía que Poddar podía estar en riesgo de cometer lesiones autolíticas y/o a otros con motivo, según Moore, de una reacción esquizofrénica paranoide. Ante esto, la policía del campus lo detuvo, pero ante la mediación del director de Psiquiatría del centro asistencial, una vez evaluado que la crisis había remitido, Poddar fue puesto en libertad. Además, se le ordenó a Moore la destrucción de la carta enviada a la policía así como las notas e informes de la terapia. En Octubre de ese mismo año, tras el regreso de Tatiana de Brasil, ésta comenzó a ser acosada de nuevo por Poddar. Ante los nuevos rechazos de ésta, el 29 de Octubre Poddar acaba con la vida de Tatiana apuñalándola.

Poddar fue deportado a la India y los padres de la víctima presentaron una demanda contra la Universidad de California y sus psicoterapeutas por no haber puesto en conocimiento de su hija el peligro que corría. Es a raíz de este caso cuando la Corte Suprema de California legisló el deber de los profesionales de salud mental de avisar a terceros que, identificados como potenciales víctimas, surjan en el transcurso del tratamiento con el paciente, aunque no hubiera ninguna relación entre el profesional y la posible víctima (3). Esto sentó las bases para que la legislación que surgió del caso Tarasoff fuera adoptada por otros Estados.

En la literatura fueron apareciendo recomendaciones a tener en cuenta para tomar una decisión sobre si el profesional debe avisar a un tercero de una amenaza por parte del paciente, como las que ahora reflejamos (4): 
ORIGINALES Y REVISIONES

1) Éste debe explicitar una intención de matar o provocar dolor físico (no valen las suposiciones).

2) La víctima es un tercero identificado (es una amenaza específica y particular).

3) Habría que evaluar si existe la capacidad física o mental para poder llevar a cabo la amenaza.

4) Considerar si el paciente tiene historia de violencia física.

5) Tener en cuenta que un profesional no tiene ningún deber de actuar de manera que pueda poner en peligro la propia vida o aumentar el riesgo de la víctima potencial.

6) Consultar a compañeros de profesión y/o a un abogado.

7) Tener en cuenta que las notas que se tomen en consulta deben ser muy precisas y detalladas, ya que en caso contrario la amenaza podría ser cuestionada por otros.

Si con los criterios anteriormente descritos se llega a la conclusión de que el peligro es real, el profesional, dicen las recomendaciones, debe tomar precauciones razonables pudiendo tener distintos niveles de actuación:

1) Comunicar a la víctima su situación de riesgo.

2) Notificar a la policía o las autoridades correspondientes.

3) Acordar con el paciente su hospitalización voluntaria.

4) En el caso de que el paciente la rechazase, se podría proceder a un ingreso involuntario.

\section{B) Caso Davis vs. Lhim}

La amenaza por parte del paciente no es siempre explícita, lo cual puede dificultar la emisión de un juicio clínico del profesional de la salud mental sobre la potencial peligrosidad para terceros. Esto se evidencia en el caso Davis vs. Lhim, ocurrido en 1975 en el estado de Michigan, EEUU. El Dr. Lhim, psiquiatra del Northville State Hospital, proporcionó tratamiento psiquiátrico hospitalario a John Patterson desde el 17 de julio al 4 de agosto de 1975 y desde el 21 de agosto al 3 de septiembre del mismo año, realizando un diagnóstico de esquizofrenia. Fue en el segundo ingreso cuando Patterson pidió el alta voluntaria y Lhim, al no encontrar ningún criterio para la retención involuntaria, se la concedió. Tras el alta, Patterson fue visto por otro psiquiatra que, al igual que el Dr. Lhim, tampoco encontró criterios para una hospitalización involuntaria. Tras dos meses del alta del Hospital Northville y unos días después de ser visto por el segundo psiquiatra, que tampoco encontró criterios de ingreso involuntario, Patterson comenzó a disparar con una pistola de manera aleatoria y cuando su madre trató de detenerle, murió a consecuencia de uno de estos disparos.

La tía de Patterson denunció al Dr. Lhim por haber aceptado el alta voluntaria de su sobrino de forma negligente y por no haber avisado a la madre de que Patterson era un peligro para su seguridad. Tras el juicio celebrado en 1983, el Dr. Lhim fue declarado culpable y recurrió el veredicto. 
Distintas Asociaciones de Psicología propusieron una serie de argumentos en relación con el caso. En primer lugar, no había evidencia de comportamiento violento de Patterson anteriormente; en segundo lugar, la única evidencia que se expuso en el juicio fue un registro en la sala de urgencias del Hospital General de Detroit de hacía dos años en las que Patterson actuaba de manera extraña y profería amenazas a su madre para que le diese dinero. El Dr. Lhim fue informado de tales amenazas, pero consideró que estaban controladas, situadas en el contexto donde tuvieron lugar y que no representaban un peligro actual ni futuro de violencia como para ser ingresado involuntariamente bajo la Ley de Michigan.

También se argumentaba en la literatura científica que los psicoterapeutas no pueden garantizar que los comportamientos futuros de los pacientes sean tal y como ellos esperan. Además, imponer a los profesionales de la salud mental el doble deber de proteger al paciente y a víctimas potenciales del mismo, entra en conflicto con las obligaciones de los psicólogos y psiquiatras de no revelar confidencias hechas por el paciente. La violación de la confidencialidad podría afectar de manera significativa a la efectividad y adherencia a la terapia, como consecuencia de pérdida de confianza hacia el terapeuta. Por otra parte, podría darse el caso de que pacientes violentos no fueran tratados, al negarse los profesionales a hacerlo, por miedo a las consecuencias legales.

Se argumentaba, además, que responsabilizar legalmente al terapeuta de los actos de sus pacientes derivaría en una sobreestimación del número de casos de pacientes violentos que finalmente podrían recurrir a la violencia. Dicha sobreestimación afectaría, sobre todo, a los propios pacientes ya que son sus confidencias las que serían puestas en conocimiento de sus familiares, amigos, etc., o bien los que tendrían que permanecer hospitalizados más tiempo de forma crónica para evitar que el paciente agrediese y el terapeuta fuese imputado. Por otra parte, el aislamiento que conlleva la hospitalización podría generar mayores impedimentos de cara a un tratamiento futuro e incluso dificultar la reinserción social.

El argumento de que el paciente se aleje del Sistema Sanitario si éste llega a contemplar la posibilidad de ruptura del secreto profesional ha sido muy utilizado. Según una encuesta realizada a un grupo de psicoterapeutas por la revista jurídica Standford Law Review tras la decisión Tarasoff, la mayoría opinó que si el paciente era consciente de que el terapeuta podría romper la confidencialidad si éste informase de la existencia de impulsos violentos, sería muy probable que el paciente ocultase dichos pensamientos al terapeuta e incluso podría evitar acudir a tratamiento, aumentando así la probabilidad de llevar a cabo dichos impulsos (5).

C) Caso W. vs. Edgell

Un caso excepcional donde primó la protección de la población fue el caso de W. vs Edgell en 1990. Tras evaluar el Dr. Edgell que uno de sus pacientes suponía un potencial peligro público, dado que presentaba un alto grado de agresividad y de ries- 
ORIGINALES Y REVISIONES

go de violencia hacia otros, decidió romper la confidencialidad y emitir un informe a las autoridades sanitarias. El juez determinó que primaba el interés público sobre el interés particular del paciente y, por tanto, que estaba justificado informar (6)(7).

\section{D) Caso Clunis}

Una cuestión que merece la pena plantear es el grado de control y responsabilidad de las personas sobre sus impulsos emocionales y sus acciones. Las emociones, al no tener connotación moral, no son calificables como buenas ni malas, sino como adaptativas o desadaptativas. Lo que hacemos con ellas, sin embargo, sí está sujeto a valoración y puede traer graves consecuencias si va en contra de lo moral y/o legalmente aceptado. Pero, ¿qué ocurre cuando entra en juego un trastorno mental? ¿Está la persona sujeta al mismo grado de responsabilidad por sus actos? En el caso Clunis, Mr. Clunis alegó no ser responsable por haber matado a una persona, apelando a su condición psiquiátrica, y acusó a las autoridades sanitarias de negligencia. Los criterios de este caso sugieren el posible deber de los psiquiatras de prevenir que sus pacientes actúen de manera violenta si no son conscientes de lo que hacen o no saben que lo que hacen está mal. En el caso Clunis, no se aceptó que Mr. Clunis estuviera exento de responsabilidad debido a su enfermedad mental y por tanto, el psiquiatra no fue imputado (6).

\subsection{Análisis deontológico}

La actividad profesional del psicólogo está orientada también por el código deontológico del Colegio Oficial de Psicólogos de España. Para el caso que aquí nos compete, comentaremos aquellos artículos que mejor se ajustan al problema.

Toda la información acerca de pacientes o clientes que recoge el psicólogo en el ejercicio de su profesión, está sujeto al cumplimiento del secreto profesional y solo podrá ser eximido de éste por autorización expresa del paciente (1).

Cuando un psicólogo en el ejercicio de su profesión obtuviese información sobre trato cruel, violento o de violación de los derechos humanos, éste deberá al menos informar a los organismos colegiales (8). En el caso expuesto no hay pruebas certeras de violencia consumada, solo hay factores de riesgo, por tanto no parece aplicable el articulo mencionado al carecer éste de potencialidad preventiva. La European Federation Psychologist Association (EFPA, 1995) también reconoce la dificultad en respetar la confidencialidad cuando es necesario proteger a un tercero identificado.

En el caso de que el psicólogo se vea inmerso en una situación en la que entran en conflicto las normas del código deontológico o de la legislación, lo que plantea es el deber de informar a los organismos colegiales y a las partes implicadas (9). Los códigos deontológicos tienden a elevar la resolución del conflicto a otros intervinientes que no están directamente implicados. 
Nos puede ser útil la referencia de otros códigos deontológicos de profesiones afines. El código deontológico médico español (2011) recoge varias excepciones a la confidencialidad y secreto médico (10):

a) En las enfermedades de declaración obligatoria.

b) En las certificaciones de nacimiento y defunción.

c) Si con su silencio diera lugar a un perjuicio al propio paciente o a otras personas, $\mathrm{o}$ a un peligro colectivo.

d) Cuando se vea injustamente perjudicado por mantener el secreto del paciente y éste permita tal situación.

e) En caso de malos tratos, especialmente a niños, ancianos y discapacitados psíquicos o actos de agresión sexual.

f) Cuando sea llamado por el Colegio a testificar en materia disciplinaria.

g) Aunque el paciente lo autorice, el médico procurara siempre mantener el secreto por la importancia que tiene la confianza de la sociedad en la confidencialidad profesional.

h) Por imperativo legal:

1. En el parte de lesiones, que todo médico viene obligado a enviar al juez cuando asiste a un lesionado.

2. Cuando actúe como perito, inspector, médico forense, juez instructor o similar.

3. Ante el requerimiento en un proceso judicial por presunto delito, que precise de la aportación del historial médico del paciente, el médico dará a conocer al juez que éticamente está obligado a guardar el secreto profesional y procurará aportar exclusivamente los datos necesarios y ajustados al caso concreto.

Los códigos deontológicos (11) son un referente importante para los profesionales, no obstante, presentan algunas limitaciones. En primer lugar centran su atención en los deberes de los profesionales, lo cual no significa que atiendan de manera significativa los derechos de los usuarios; dicho de otro modo, es una visión excesivamente unilateral. Por otro lado, nuestro código está hecho por y para los psicólogos, con lo cual puede tener un sesgo excesivamente corporativo. Finalmente, los códigos deontológicos no pueden recoger la riqueza ni complejidad de la vida clínica, con lo cual necesitamos otras herramientas para hacer la valoración moral de los casos. Nosotros como profesionales tenemos la responsabilidad de conocer nuestro código deontológico, ahora bien, su función es la de iluminar pero no la de prescribir.

\subsection{Análisis jurídico}

Aún a sabiendas que no tienen por qué coincidir la valoración ética y el análisis jurídico, también es importante contemplar este último porque habla de lo 
ORIGINALES Y REVISIONES

que piensa la mayoría moral a través de lo que se recoge en el derecho positivo. Teniendo en cuenta que el caso que aquí relatamos sucedió en España, conviene conocer lo que dicen las leyes españolas al respecto y, más concretamente, la ley penal sobre infidelidad en la custodia de documentos y de la violación de secretos. Según Júdez, J. et al. (2001) (12), en el Código Penal (1995) la obligación de confidencialidad es aplicable a todos los profesionales. Por profesionales, en este contexto, entendemos "aquél que cumple los siguientes requisitos: ejercicio de un empleo, facultad u oficio; ejercicio público jurídicamente reglamentado (investidura pública); y necesidad de requerir tales servicios (confidente necesario)" (Bajo, M., 1980 citado en Júdez, J. et al., 2001). La obligación de confidencialidad se recoge de esta forma en el artículo 199 del Código Penal (13):

"1. El que revelare secretos ajenos, de los que tenga conocimiento por razón de su oficio o sus relaciones laborales, será castigado con la pena de prisión de uno a tres años y multa de seis a doce meses. 2. El profesional que, con incumplimiento de su obligación de sigilo o reserva, divulgue los secretos de otra persona, será castigado con la pena de prisión de uno a cuatro años, multa de doce a veinticuatro meses e inhabilitación especial para dicha profesión por tiempo de dos a seis años".

En el caso de que un profesional sanitario revelase improcedentemente un secreto que por su cargo obtuviese y dañase al particular, tercero o causa pública podrá ser imputado según los artículos 417 y 418 del capítulo IV del código penal español (1995) (Puede consultarse tabla 1).

Además, el artículo 7 de la ley 41/2002 de 14 noviembre básica reguladora de la autonomía del paciente y de derechos y de obligaciones en materia de información y documentación clínica afirma:

"1. Toda persona tiene derecho a que se respete el carácter confidencial de los datos referentes a su salud, y a que nadie pueda acceder a ellos sin previa autorización amparada por la Ley".

"2. Los centros sanitarios adoptarán las medidas oportunas para garantizar los derechos a que se refiere el apartado anterior, y elaborarán, cuando proceda, las normas y los procedimientos protocolizados que garanticen el acceso legal a los datos de los pacientes." 
Tabla 1.

Capítulo IV Código Penal.

\section{Capitulo IV código penal}

Articulo 417 pr.1 La autoridad o funcionario público que revelare secretos o informaciones de los que tenga conocimiento por razón de su oficio o cargo y que no deban ser divulgados, incurrirá en la pena de multa de doce a dieciocho meses e inhabilitación especial para empleo o cargo público por tiempo de uno a tres años.

Art 417, pr.2 Si se tratara de secretos de un particular, las penas serán las de prisión de dos a cuatro años, multa de doce a dieciocho meses y suspensión de empleo o cargo público por tiempo de uno a tres años.

Art 418 El particular que aprovechare para sí o para un tercero el secreto do la información privilegiada que obtuviere de un funcionario público o autoridad, será castigado con multa del tanto al triplo del beneficio obtenido o facilitado. Si resultara grave daño para la causa pública o para tercero, la pena será de prisión de uno a seis años.

Los psicólogos hemos de conocer la realidad jurídica en torno a nuestras actuaciones. No solo por una cuestión de conocimiento de nuestras obligaciones legales, sino también por el conocimiento de los derechos que tanto el paciente o cliente, como nosotros, podemos disfrutar. Ahora bien, el riesgo de atenernos en sentido estricto a los criterios que marca el derecho positivo puede conducirnos a una psicología defensiva con el objetivo prioritario de protegernos de determinadas demandas judiciales. Si ése es el criterio fundamental entendemos que estamos perdiendo la perspectiva. De todos es sabido que hay leyes que sin ser injustas pueden ser inmorales y que cuando hay conflicto entre la ley y determinados valores éticos nuestra responsabilidad ha de priorizar la misión inherente a los valores internos de la profesión, es decir, el tratamiento y cuidado psicológico de las personas.

\section{Breve exposición de un método de análisis ético}

La bioética moderna ha elaborado distintos métodos para el análisis de las situaciones que plantean conflictos éticos en el ámbito clínico. Vamos a exponer brevemente uno de esos métodos, basado en la deliberación moral, desarrollado fundamentalmente por el profesor Diego Gracia (2001) (2), uno de los pensadores que más ha influido en esta materia. Este autor defiende que para la toma de decisiones han de tenerse en cuenta los principales actores y factores implicados, con un determinado procedimiento, evitando así una toma de decisiones basada en un más que cuestionable "olfato moral". Aquellos que toman decisiones de manera automática, creyendo tener la respuesta de antemano, están actuando en base a su inseguridad y a su miedo en el proceso deliberativo. Estas personas, dominadas 
ORIGINALES Y REVISIONES

por su angustia, transforman los problemas en dilemas planteando su resolución de manera dicotómica, de todo o nada, sin tener en cuenta cursos intermedios de acción que pueden dañar lo menos posible las valores que están en conflicto.

La deliberación es un proceso de análisis crítico y conjunto de un caso clínico que consta de una serie de pasos básicos:

1) Discusión de los aspectos clínicos del caso.

2) Identificación de los problemas morales que presenta.

3) Elección del problema moral más significativo o que más preocupa.

4) Identificación de los valores en conflicto prevalentes.

5) Identificación de los cursos extremos de acción posibles.

6) Identificación de los cursos intermedios de acción posibles.

7) Deliberación sobre el/los curso(s) de acción óptimo(s).

8) Decisión final.

9) Aplicación de tres criterios reguladores de la decisión tomada: si respeta el marco jurídico, si estaríamos dispuestos a defenderlo en público y si tomaríamos la misma decisión en caso de contar con más tiempo.

La identificación de los valores en conflicto puede ser formulada en forma de principios, normas, actitudes. Lo importante es que se clarifique qué es lo que está en juego. La identificación de los cursos extremos nos permite saber cuál es la horquilla entre la que se encuentran las posibles decisiones, pero sobre todo, nos permite detectar qué decisiones hay que evitar, porque suponen una transgresión muy radical de cualquier de los valores implicados. Uno de los momentos más interesantes del método es la búsqueda conjunta de los cursos intermedios de acción, porque la deliberación sobre ese punto suele abrir enormemente el caudal de posibilidades y ampliar las perspectivas, evitando un posicionamiento dilemático de blanco o negro. El último punto, que explicita tres criterios reguladores, permite poder tener una perspectiva más global del asunto y no encerrarse en las categorías tan concretas y específicas de cualquier caso particular. Es decir, si alguna decisión va en contra del ordenamiento jurídico o no nos atrevemos a defenderla en público o puede estar muy condicionada a la precipitación que supone la falta de tiempo, nos ha de llevar a preguntarnos si estamos por el buen camino en la reflexión y en el proceso de toma de decisiones.

Esta metodología está ampliamente contrastada en el mundo de la bioética, inclusive con respecto a temas tan específicos como el del secreto profesional y la confidencialidad (14) que determinan este caso. 


\section{Aplicación de este método de análisis al caso concreto}

Los aspectos clínicos del caso han sido comentados en el comienzo del artículo. Sí que carecemos de información posiblemente relevante en torno a la estructura y la dinámica familiar. Es cierto que, hasta el momento, el paciente se ha negado a que comentemos con su familia la situación, no tanto del posible riesgo para el hermano conviviente -no se le ha planteado directamente- sino la posibilidad de conseguir mejores apoyos sociofamiliares para una vida significativamente tediosa y poco motivante. También parece relevante el análisis clínico de la capacidad del sujeto para la toma de decisiones. Algunos autores ubican esta parte en la detección de problemas éticos. Independientemente del lugar metodológico lo importante es valorar esa capacidad. A priori, mientras no se demuestre lo contrario, todo sujeto es competente para tomar decisiones sobre su proyecto vital. Él no tiene por qué justificar que lo es; en todo caso, a los profesionales nos tocaría probar que no tiene esa competencia, de haber dudas razonables sobre la misma. En el caso que aquí nos ocupa, el paciente no padece ningún déficit cognitivo importante y las alteraciones emocionales de corte depresivo, derivadas del peso de convivir con dos enfermedades crónicas tan amenazantes, no alteran significativamente su capacidad de juicio para tomar decisiones. Una decisión moralmente autónoma ha de ser una decisión informada, voluntaria (es decir, ni manipulada ni coaccionada) y realizada por un sujeto capaz. En principio, el paciente del que hablamos en circunstancias normales está tomando decisiones autónomas. Cosa distinta es la valoración de su capacidad de autorregulación y de control de impulsos ante una situación particular amenazante y, en ese momento, inesperada.

En este tipo de situaciones parece fundamental realizar dos tipos de valoraciones, las cuales obviamente tienen un carácter hipotético. En principio la valoración del riesgo real de homicidio. La ideación homicida, ¿es expresión básicamente de indignación y de saturación personal? ¿Es la expresión de una queja que uno necesita explicitar en un ámbito terapéutico para poder ser acogida? ¿Es una petición de auxilio indirecta de un paciente angustiado para que los terapeutas o el sistema le ayudemos a poner límites? En nuestro caso entendimos que el riesgo era teóricamente posible pero podía ser en la práctica realmente improbable si se le confrontaba en la dimensión ética de la conducta y sobre las consecuencias previsibles para él y para su entorno, tanto vitales, emocionales como jurídicas. Por otra parte, se valoró la posible intervención de otros profesionales como posteriormente matizaremos para promover una disminución del riesgo. En segundo lugar, parece fundamental la valoración del riesgo de suicidio en el paciente si hay una ruptura del secreto profesional y se avisa a la víctima potencial y a otros familiares de la posibilidad de la agresión. En nuestro caso también existe riesgo, dado el grado de humillación ya experimentado y la dificultad que podía experimentar el paciente ante una confrontación previsiblemente agresiva de su propio hermano. 
ORIGINALES Y REVISIONES

Los problemas éticos que aparecen en este caso en concreto son:

- Riesgo de agresión mortal a un tercero identificado, en particular, su hermano conviviente.

- ¿Existe el deber de informar y avisar?

- En caso de existir el deber de informar, ¿a quién hay que hacerlo? ¿Al hermano del paciente, a las autoridades sanitarias, a las autoridades policiales o judiciales?

- Riesgo de infección de VIH al hermano, en la posible confrontación física.

- El deber o el derecho de informar del conflicto y del riesgo a otros profesionales que también han estado atendiéndole (médico y enfermera de Atención Primaria, médicos hematólogos que le tratan la hemofilia, profesionales del Servicio de Medicina Interna que le controlan el VIH...), sobre todo cuando él explícitamente exige que no se les diga nada.

El problema principal sería valorar si estaría justificada la ruptura del secreto profesional ante el riesgo de una conducta agresiva, potencialmente mortal, del paciente hacia su hermano conviviente.

Los valores que entran en conflicto, que podemos describir como principios éticos, normas, actitudes, derechos, etc., podrían ser:

1) Principio de no maleficencia.

2) Principio de autonomía.

3) Confianza terapéutica, que permite que un paciente desvele sus preocupaciones.

4) Vínculo terapéutico con el terapeuta y con el sistema sanitario.

5) Peso otorgado al código deontológico de la profesión.

6) Deber de socorro, que puede ser transgredido por omisión.

7) Salud o vida del hermano.

8) Proceso comunicativo y empleo de estrategias adecuadas.

Los cursos extremos de acción hacen referencia a decisiones que dañan significativamente un valor; sin embargo, es importante identificarlos para poder establecer los límites de la acción y por tanto plantear los posibles cursos intermedios. En este caso, los cursos extremos serían:

a) Que el terapeuta no informe a nadie y, además, no haga nada por persuadir al paciente en alternativas con menos riesgos para un tercero. Este curso transgrede sustancialmente al principio de no maleficencia.

b) Al terminar la consulta se llama a la víctima potencial o/y a otros familiares o/y a la policía. Este curso transgrede claramente el principio de autonomía.

Como cursos intermedios de acción, señalamos como posibles:

a) Informar al Jefe de Servicio del conflicto y pedir su opinión.

b) Pedir asesoría en distintos ámbitos: sesión clínico-ética con el equipo de psicólogos del Servicio, petición de informe asesor al Comité de Ética para la Asis- 
tencia Sanitaria (CEAS) del hospital; consulta con el comité deontológico del Colegio Oficial de Psicólogos; supervisión del caso con otros psicólogos externos.

c) Confrontar al paciente con escenarios de consecuencias menos dañinas para él y para su hermano (cambio de residencia, continuar el trabajo psicoterapéutico que facilite un buen manejo de la rabia y un mejor control de impulsos, etc.).

d) Contactar con los profesionales de Atención Primaria, tanto médico como enfermera, para recabar información sobre la familia y su funcionamiento, puesto que muy posiblemente esté toda la familia adscrita al mismo centro de salud, dado que los hermanos habitan todos en lugares cercanos.

e) Hablar con el paciente, expresarle nuevamente nuestro deseo de ponernos en contacto con sus hermanos y pedirle consentimiento.

f) Hablar con los hermanos no implicados en la convivencia, para una posible función mediadora en el conflicto, conceda o no conceda consentimiento para ello.

Continuamos con la deliberación sobre los cursos de acción óptimos. La petición de asesoría es una medida necesaria, que puede iluminar los posibles cursos de acción, dado que un análisis de gente con formación y experiencia que no están involucrados directamente en la asistencia del sujeto, puede abrir otras vías y puede aportar mayor objetividad al conflicto. La confrontación con el paciente también es una responsabilidad exigible al psicoterapeuta, siempre y cuando lo haga de una determinada manera que minimice el riesgo de ruptura de la relación y de la confianza depositada en esa relación. Toda confrontación sin acogida acaba siendo una agresión (15). Parece importante en ese proceso terapéutico explicitar con el paciente los valores que hay en juego y las consecuencias posibles de los distintos actos y escenarios. Por ejemplo, colocarse en una situación de riesgo vital también para él mismo puede suponer un acto equivalente a un intento larvado de suicidio. Es decir, en ocasiones hay personas que ante el miedo a tomar una decisión suicida se colocan a sí mismos en situaciones de riesgo vital provocadas por ellos mismos. Con respecto al hecho de ponernos en contacto con sus otros hermanos no convivientes y hacerlo con o sin consentimiento, conviene tener en cuenta los siguientes aspectos: la exploración y búsqueda de ayuda externa en el medio familiar o comunitario de los pacientes es una estrategia habitual que se trabaja en la consulta. En ocasiones, sugiriéndolo al propio paciente para que sea capaz de demandar ayudas en el entorno y, en otras ocasiones, siendo el propio profesional el que busca información añadida para tener más datos y manejar así mejor el problema. Por citar un ejemplo, decir que hay muchos profesionales del ámbito hospitalario que conectan con los compañeros de Atención Primaria presuponiendo un consentimiento implícito dadas las reservas en el manejo de la información dentro del propio espacio profesional. La petición de ayuda a familiares suele hacerse con consentimiento explícito de los pacientes. En el caso que aquí nos ocupa, parecía 
ORIGINALES Y REVISIONES

indicado conectar con el médico y el enfermero de su centro de salud, al que también posiblemente estarían adscritos sus hermanos, para investigar más a fondo la estructura y dinámica familiar. Lo haríamos sin petición expresa de consentimiento al paciente, dado su habitual negativismo y dado que es una práctica común entre profesionales, guiada por criterios de prudencia y confidencialidad. Por otra parte, sería conveniente seguir insistiendo al paciente en la necesidad de conectar con algún familiar de su confianza que pudiera hacer de informador clave y de facilitador de posibles y ulteriores alternativas. Inicialmente se prefiere no localizarlos sin su consentimiento, por los riesgos que conlleva de ruptura de la relación terapéutica.

Es muy importante considerar todo este tipo de posibles acciones dentro de una línea de proceso. La dimensión temporal acaba siendo central. ¿Cuánto tiempo es prudente esperar, mientras se realizan determinados cursos intermedios de acción, asumiendo el riesgo de que se precipiten los hechos de agresividad? Estamos ante la cuestión de la valoración de riesgos y del mundo de las probabilidades. A nuestro entender, el hecho de que el paciente haya pedido ayuda psicológica y haya explicitado el conflicto supone que la propia terapia se convierte en un lugar de canalización de ansiedades y de ordenación de parámetros centrales para las distintas tomas de decisiones. Dicho de otro modo, el conflicto sigue estando, pero tiene un lugar y un tiempo (la consulta) para ir trabajándolo externamente y metabolizándolo internamente. Esto supone un plus de ansiedad para el terapeuta, el cual, si no tuviera en cuenta estas consideraciones, corre el riesgo de caer en una actitud básicamente defensiva y autoprotectora, al no saber o poder manejar la angustia que supone la existencia de la situación de riesgo. Obviamente la espera no puede ser sine die, sino que necesite estar cargada de contenido terapéutico en el desarrollo de dicho proceso. Ahora bien, en estos momentos, la sensación es que el espacio terapéutico está sirviendo para contener el riesgo.

En definitiva, ¿qué vamos a hacer ante la situación concreta del paciente en particular? Después de buscar asesoramiento y de informar a nuestros jefes de la situación decidimos seguir los siguientes cursos de acción:

1) Explorar más datos de la estructura y funcionamiento familiar con el médico y enfermera de Atención Primaria del centro de salud del que son potenciales usuarios el paciente y sus hermanos. La información que recibimos es la de una familia de estructura frágil y con escasa dinámica de apoyo mutuo. Los profesionales del centro de salud sí que estiman que la situación es de riesgo significativo.

2) Se contacta con la cuñada del paciente, que él nos había presentado hace tiempo como acompañante a una consulta médica del hospital, por ser la única persona de la que explícitamente él habla como elemento de apoyo intrafamiliar. Este contacto lo hacemos entendiendo que hay un consentimiento implícito del paciente porque comenta su presencia en distintas ocasiones señalándola como una persona muy importante y de mucho apoyo para él, diciéndonos que es una persona 
"de máxima confianza". Somos conscientes de que el contacto se hace sin consentimiento explícito, pero entendemos que es una cuestión éticamente calificable como mal menor. Mantenemos esa entrevista y pulsamos el riesgo percibido y la capacidad de apoyo familiar en la búsqueda de alternativas. La cuñada afirma que estará especialmente atenta a los posibles desajustes de conflicto del paciente con el hermano conviviente para incidir de manera preventiva. La experiencia nos confirmó que no podíamos obviar la participación de un recurso tan importante.

3) Se introduce de manera más intensiva la deliberación moral con el paciente en el espacio psicoterapéutico promoviendo un análisis ético de los posibles hechos y consecuencias en torno a una conducta agresiva. En esa deliberación se explicita al paciente el conflicto moral al que sitúa al profesional con los datos que el aporta. De hecho, el paciente reconoce que el comentarlo en consulta era una manera de petición de ayuda.

4) Se valoran las consecuencias de la ruptura del secreto profesional destacando la pérdida de confianza con casi el único eslabón que tenía de contacto actual con la red sanitaria, el único dispositivo que permitía favorecer alternativas a la conducta agresiva. Tampoco era descartable la aparición de diseño o intento suicida. Por otro lado, la ruptura del secreto realizada a las autoridades podría provocar una acción de las mismas con objetivo preventivo pero claramente maleficente para el paciente ¿Qué se podría hacer? ¿Detener a una persona cuyas agresiones no han ocurrido? ¿Agudizar el conflicto con el hermano ante la visibilización del riesgo de agresión mutua? ¿Por cuánto tiempo se deberían de mantener las medidas preventivas? Dicho en términos coloquiales, "a veces puede ser peor el remedio que la enfermedad".

5) Se decide mantener la intervención psicoterapéutica sistemática y frecuente hasta que hayan determinados indicadores de proceso que hablen o bien de la disminución de riesgo de provocación del hermano conviviente o bien de la mejora del afrontamiento o de la búsqueda de alternativas del paciente.

La ruptura del secreto profesional solo es admisible éticamente como algo excepcional y las excepciones solo pueden ser aplicadas cuando el daño previsible es muy grave y muy probable (no vale solo que sea posible, ha de ser muy probable), lo cual ha de estar suficientemente justificado. A nosotros, los profesionales, es a quien corresponde cargar con la prueba si entendemos que el mal menor, en este caso, es la ruptura del secreto. En el caso que nos ocupa, desarrollando los cursos intermedios mencionados, no está justificada por el momento la ruptura del secreto, pues tanto la probabilidad de ocurrencia de la agresión mortal y el desarrollo de los cursos intermedios de acción estiman la no ruptura como más prudente. Cuanto más extrema es una decisión (y la ruptura del secreto lo es) más ha de estar justificada. Como es lógico necesitaremos de una evaluación continua y de una adecuada monitorización, por la gravedad de la situación de la que hablamos. 
ORIGINALES Y REVISIONES

\section{A modo de conclusión}

1) La dimensión ética en la intervención de los casos clínicos es una variable central para ser tenida en cuenta, tanto en la valoración del caso como en la estrategia terapéutica a seguir.

2) La dimensión ética también puede generar una contratransferencia en el profesional que condicione su quehacer psicoterapéutico. Un mundo de valores del paciente radicalmente distinto al nuestro puede generar animadversión, mientras que un mundo de valores similar al nuestro o que nosotros vivamos como admirable también puede distorsionar el juicio clínico y la estrategia terapéutica.

3) La valoración ética de un caso no se puede hacer por la mera intuición del profesional. La intuición, al igual que la percepción introspectiva de una determinada alteración emocional, son señales de alarma que invitan al análisis cuidadoso. Éste solo puede hacerse con una metodología sistemática suficientemente validada, como la que en este artículo hemos manejado.

4) El psicólogo trabaja también con el mundo de las emociones y las emociones son malas consejeras para el análisis moral. Por ello, es tan importante un diagnóstico diferencial del mundo emocional y del mundo axiológico. Nuestra angustia o nuestro miedo no puede ser el criterio central de la toma de decisiones.

5) El que tengamos en cuenta el mundo de los valores en conflicto no significa que el profesional no pueda hacer y tener su propia valoración ética. Significa exclusivamente que los valores son una herramienta para favorecer el bienestar psicológico de las personas, tanto en el corto como en el medio y largo plazo. En este sentido, una pretendida neutralidad moral puede ser sinónimo de indiferencia frente a los aconteceres del otro. Un psicólogo puede tener un compromiso ético con la experiencia de sufrimiento de los otros sin hacer un juicio moral respecto a la persona que tiene delante. Entre otras cosas, porque la valoración moral de las conductas puede ser congruente con la aceptación incondicional de las personas.

6) La experiencia nos dice que hay que ser enormemente cautelosos con las "actuaciones preventivas" basadas más en conjeturas que en indicios o en pruebas. Esta reflexión atañe al mundo de la política, de la economía, pero también de la actividad clínica. La aparición de factores de riesgo ha de ser medida cuidadosamente pero su presencia no equivale necesariamente a la posterior realización de la conducta temida. Tengamos en cuenta la posibilidad de estigmatizar a determinados grupos de pacientes desde esta errónea dimensión preventiva dado que personas con VIH, enfermos mentales, etc., corren el riesgo de ser calificados más por estereotipos que por factores de riesgo individualizados. Por otra parte, esta aproximación promueve los sesgos actitudinales en los terapeutas.

7) Como última reflexión, decir que el psicólogo se encuentra con la biografía y con la subjetividad. Este encuentro nos obliga a tener en cuenta, de manera mul- 
tivarial, dimensiones como los afectos, los valores, las voluntades, las relaciones, las expectativas, etc. El terreno de la subjetividad no significa necesariamente un escenario de incertidumbre. Tenemos métodos suficientes y validados para poder explorar territorios particulares tan teóricamente insondables como es el mundo de los valores.

\section{BIBLIOGRAFIA:}

(1) Colegios Oficiales de Psicólogos. Código deontológico del Psicólogo. Madrid: Consejo General de Colegios Oficiales de Psicólogos, 2010. Cap. V, art. 40. URL: http://www.cop.es/pdf/CodigoDeontologico-Consejo-Adaptacion-Ley-Omnibus.pdf [visita 4 octubre 2012].

(2) Gracia D. La deliberación moral: el método de la ética clínica. Medicina Clínica (Barc) 2001; 117(1):18-23.

(3) Turner M., Kennedy M. Tarasoff and the duty to warn third parties. Psychiatric Bulletin $1997 ; 21: 465-466$.

(4) Fleming M. [Unpublished lecture notes on Counselling and Motivational Interviewing]. Boston University; notes provided 23/02/2009.

(5) Klein J, Smith MP. Brief of Amici Curiae American Psychological Association, Michigan Psychological Society, Michigan Psychiatric Society in Support of Defendant Appellant. 1983, Washington D.C: Wilson - Efes Printing co.,inc.

(6) Adshead G. Duties of Psychiatrists: Treat the Patient or Protect the Public? Advances in Psychiatric Treatment 1999, 5:321-328, doi:10.1192/apt.5.5.231.

(7) Harbour A. Limits of confidentiality. Advances in Psychiatric Treatment 1998; 4:66-69 doi:10.1192/apt.4.2.66.

(8) Colegios Oficiales de Psicólogos. Código deontológico del Psicólogo. Madrid: Consejo General de Colegios Oficiales de Psicólogos, 2010. Cap. I, art. 8. URL: http://www.cop.es/pdf/CodigoDeontologico-Consejo-Adaptacion-Ley-Omnibus.pdf [visita 4 octubre 2012].

(9) Colegios Oficiales de Psicólogos. Código deontológico del Psicólogo. Madrid: Consejo General de Colegios Oficiales de Psicólogos, 2010. Cap. VIII, art 61. URL: http://www.cop.es/pdf/ Codigo-Deontologico-Consejo-Adaptacion-Ley-Omnibus.pdf [visita 4 octubre 2012].

(10) Organización Médica Colegial. Código de Ética y Deontología Médica. Madrid: Organización Médica Colegial, 2011. Cap. V, art. 30. URL: https://www.cgcom.es/sites/default/files/ codigo_deontologia_medica.pdf [visita 4 octubre 2012].

(11) Simón P. Sobre Bioética y Deontología Médica. Cuadernos de Bioética 1992; 12 (4): 34-37.

(12) Júdez J, Nicolás P, Delgado M, Hernando P, Zarco J, Granollers S. La confidencialidad en la práctica clínica: Confidencialidad, historia clínica y gestión de la información. Med Clin (Barc) 2002; 118(1):18-37.

(13) Ley Orgánica 10/1995 de 23 de noviembre, del Código Penal. Publicado en el BOE núm 281 de 24 de noviembre de 1995, 33987 a 34058. URL: http://www.boe.es/boe/dias/1995/11/24/pdfs/A3398734058.pdf [visita 4 octubre 2012]. 
ORIGINALES Y REVISIONES

(14) Bertrán JM, Collazo E, Gérvas J, González Salinas P, Gracia D, Júdez J, Rodríguez JJ, Rubí J, Sánchez M. Intimidad, confidencialidad y secreto. Guías éticas en la práctica médica. Madrid: Edición Ergón, 2005.

(15) Barbero J. Humanización: ¿Tecnología Punta? En: Bermejo JC (ed). Salir de la noche. Por una enfermería humanizada. Santander: Sal Terrae, 1999; 49-57. 